\title{
Microwave Assisted Synthesis of ZnO Nanoparticles: Effect of Precursor Reagents, Temperature, Irradiation Time, and Additives on Nano-ZnO Morphology Development
}

\author{
Gastón P. Barreto, Graciela Morales, and Ma. Luisa López Quintanilla \\ Centro de Investigación en Química Aplicada, Boulevard Enrique Reyna 140, 25253 Saltillo, COAH, Mexico \\ Correspondence should be addressed to Gastón P. Barreto; gbarreto@fio.unicen.edu.ar
}

Received 27 December 2012; Accepted 26 March 2013

Academic Editor: Antoni Morawski

Copyright (c) 2013 Gastón P. Barreto et al. This is an open access article distributed under the Creative Commons Attribution License, which permits unrestricted use, distribution, and reproduction in any medium, provided the original work is properly cited.

\begin{abstract}
The effect of different variables (precursor reagents, temperature, irradiation time, microwave radiation power, and additives addition) on the final morphology of nano- $\mathrm{ZnO}$ obtained through the microwave assisted technique has been investigated. The characterization of the samples has been carried out by field emission scanning electron microscopy (FE-SEM) in transmission mode, infrared (FTIR), UV-Vis spectroscopy, and powder X-ray diffraction (XRD). The results showed that all the above-mentioned variables influencedto some extent the shape and/or size of the synthetized nanoparticles. In particular, the addition of an anionic surfactant (sodium di-2-ethylhexyl-sulfosuccinate (AOT)) to the reaction mixture allowed the synthesis of smaller hexagonal prismatic particles $(100 \mathrm{~nm})$, which show a significant increase in UV absorption.
\end{abstract}

\section{Introduction}

$\mathrm{ZnO}$ powder has been widely used into numerous materials and products including paints, plastics, ceramics, and adhesives. It is a semiconductor of the II-VI semiconductor group with several favorable properties such as high electron mobility, wideband gap, and strong room temperature luminescence. These properties make $\mathrm{ZnO}$ an attractive compound for different emerging applications.

In the last two decades many methods ranging from gasphase processes to solution routes have been investigated for the synthesis of $\mathrm{ZnO}$ nanoparticles including solution precipitation $[1,2]$, spray pyrolysis $[3,4]$, hydrothermal synthesis [5-7], sol-gel processes [8-11], and microemulsion synthesis [12].

In cases where the synthesis has been carried out through a conventional thermostatic system, the walls of the reactor are heated by convection or conduction, the core of the sample needs longer time to achieve the target temperature, and this may result in inhomogeneous temperature profiles. One possible solution to this problem is the use of microwave heating, which has become a very promising method of synthesis for both organic [13, 14], and inorganic [15] chemistry. This technique enables the rapid and homogenous heating of the reaction mixture to the desire temperature, which saves time and energy.

The microwave heating is based on two conversion mechanisms of the electromagnetic radiation into heat energy, namely, dipolar rotation and ionic conduction, which are directly related to the chemistry composition of the reaction mixture. So that, different compounds have different microwave absorbing properties, and this behavior allows a selective heating of compounds in the reaction mixture.

The general advantages of microwave mediated synthesis over conventional ones are (1) reaction rate acceleration as a consequence of high heating rates, (2) wide range of reaction conditions, that is, mild conditions or autoclave conditions, (3) high reaction yields, (4) reaction selectivity due to different microwave absorbing properties, (5) excellent control over reaction conditions, and (6) simple handling, allowing simple and fast optimization of experimental parameters. 
Since 2007, the number of publications dealing with the microwave assisted synthesis of $\mathrm{ZnO}$ has increased significantly. In this sense there have been many published results concerned with aqueous and nonaqueous solution microwave assisted synthesis where the effect of different experimental variables over $\mathrm{ZnO}$ size, shape, and physicochemical behavior have been analyzed [16-18]. This irradiation technique has been used to obtain nanostructures with various morphologies including spherical particles, rods, hexagonal rings, hexagonal columns, Flowers, wires, hexagonal tubes, and sheets.

Some authors [16] demonstrated the possibility of $\mathrm{ZnO}$ synthesis with a novel three-dimensional morphology, where microwave radiation as heating source plays an important role in the formation of complex nanostructures. In addition, the absence of metal catalyst, template, or surfactant in this method avoids the subsequent effort for the removal of residual additives.

Other studies [18] dealt with the effect of power of microwave radiation on the shape and size of the synthetized $\mathrm{ZnO}$ nanostructures, where the average particle size decreases with decreasing microwave power being the optical properties sensitive to the variation of this parameter.

On the other hand, other authors [19] analyzed the effect of solvent (water, ethanol, and isopropanol) on the synthetized $\mathrm{ZnO}$ nanostructures, and an important change in the size and shape of nanoparticles was reported. When distilled water was used as a solvent, nanoparticles presented ellipse shape and larger size (larger axis was about $100 \mathrm{~nm}$ and size of the other axis was about $40 \mathrm{~nm}$ ). With ethanol, the obtained nanostructures had rod form with smaller sizes than those obtained in water, and when isopropanol was used as the reaction medium, spherical particles with radius of $10-12 \mathrm{~nm}$ were obtained.

However, most synthetic studies did not show a complete study about different parameters involved during the microwave assisted technique. In this sense, this work deals with a complete analysis of different variables (precursor reagents, temperature, irradiation time, microwave radiation power, and the addition of additives) and their effect on the final morphology of nano- $\mathrm{ZnO}$ obtained through the microwave assisted technique.

\section{Experimental}

2.1. Synthesis of $\mathrm{ZnO}$. In a typical synthesis process, $15 \mathrm{~mL}\left(1.6 \mathrm{~mol} \mathrm{~L}^{-1}\right)$ of a precursor salt $\left(\mathrm{Zn}\left(\mathrm{NO}_{3}\right)_{2} \cdot 6 \mathrm{H}_{2} \mathrm{O}\right.$, $\mathrm{Zn}\left(\mathrm{CH}_{3} \mathrm{COO}\right)_{2} \cdot 2 \mathrm{H}_{2} \mathrm{O}$ or $\left.\mathrm{ZnCl}_{2}\right)$ were diluted in $32 \mathrm{~mL}$ of deionized water (or a sodium di-2-ethylhexyl-sulfosuccinate aqueous solution) to obtain a $\mathrm{Zn}^{+2}$ solution. Afterwards, $4 \mathrm{~mL}$ of a base $\left(3.2 \mathrm{~mol} \mathrm{~L}^{-1}\right)\left(\mathrm{NaOH}, \mathrm{KOH}\right.$, or $\left.\mathrm{NH}_{4} \mathrm{OH}\right)$ was added dropwise $(2 \mathrm{~min})$ into the above-described solution with magnetic stirring at room temperature to get a colloid system, which was maintained under stirring for $10 \mathrm{~min}$. Then, the reaction mixture was transferred into a Teflon autoclave and treated at selected temperature $(80,100$, 120 , or $\left.140^{\circ} \mathrm{C}\right)$ for specific time $(5,10$ or $20 \mathrm{~min})$ under temperature-controlled mode in a microwave accelerated reaction system (Mars-X) operating at different powers $(300,600$, or $1200 \mathrm{~W})$. It must be mentioned that the system was programmed with a first temperature ramp where the target temperature was reached after $10 \mathrm{~min}$ in all cases (Table 1). When the reaction was finished and cooled to room temperature, the white precipitate was collected by filtration and washed with deionized water and ethyl alcohol several times. Finally, the product was dried at $65^{\circ} \mathrm{C}$ in a vacuum oven for $3 \mathrm{~h}$.

2.2. Characterization. To investigate the structural properties of $\mathrm{ZnO}$ nanoparticles, field emission scanning electron microscopy (FE-SEM), infrared (FTIR), UV-Vis spectroscopy, and powder X-ray diffraction (XRD) studies were carried out. $\mathrm{ZnO}$ powders synthetized were characterized by X-ray diffraction with a Siemens D500 diffractometer. Diffraction patterns were recorded from 10 to $80^{\circ} 2 \theta$ with a step size of $0.06^{\circ}$ at $35 \mathrm{kV}$ and $25 \mathrm{~mA}$. The average crystallite sizes $D$ (Table 1 ) of the $\mathrm{ZnO}$ nanostructures were calculated using Scherrer's formula

$$
D=\frac{0.9 \lambda}{\beta \cos \theta},
$$

where $\lambda$ is the $\mathrm{X}$-ray wavelength of $\mathrm{Cu}-\mathrm{K} \alpha$ radiation source, $\beta$ is the full width at half maximum intensity of the diffraction peak located at $2 \theta$, and $\theta$ is the Bragg angle.

On the other hand, an aliquot of solid state material was placed in a carbon label for analysis by FE-SEM (JSM-7401F). Samples were analyzed using a secondary electron detector. The infrared spectra of $\mathrm{ZnO}$ nanoparticles were taken in a Nicolet spectrophotometer model Nexus 470 Nicolet brand in transmittance mode. The sample preparation was made in tablet way by mixing nano- $\mathrm{ZnO}$ and $\mathrm{KBr}$ in an agate mortar. The solid samples were dispersed in deionized water and ultrasonicated for $10 \mathrm{~min}$. Then UV-Vis spectra of colloidal systems were obtained through a Shimadzu double beam spectrophotometer model UV-2401PC.

Characterization data of all $\mathrm{ZnO}$ synthesis carried out is described in Electronic Supplementary Material (ESM) that accompanies this paper (see Supplemetary Material available online at http://dx.doi.org/10.1155/2013/478681).

\section{Results and Discussion}

3.1. Temperature Effect. The microwave system employed to synthetize the $\mathrm{ZnO}$ particles allows to set a constant reaction temperature. In order to analyze the temperature effect on the final morphology of the product obtained, the synthetic reactions were carried out in the temperature interval 80$140^{\circ} \mathrm{C}$ using $\mathrm{Zn}\left(\mathrm{NO}_{3}\right)_{2}$ as the precursor salt (from $\mathrm{MW}-1$ to MW-4, Table 1). XRD studies (Figure 1) show that, when the reaction is carried out for 20 minutes at 80 or $100^{\circ} \mathrm{C}(\mathrm{MW}-1$ and $\mathrm{MW}-2$, resp.), the signals are not clear, and some peaks attributable to precursor reagents and unknown impurities are observed. On the contrary, at 120 and $140^{\circ} \mathrm{C}$ (MW-3 and MW-4, resp.) all the diffraction peaks match those of the wurtzite $\mathrm{ZnO}$ with lattice constants of $a=3.250 \AA$ and $c=5.207 \AA$. The strong diffraction peaks appear at 
TABLE 1: Experimental conditions employed during microwave assisted synthesis of $\mathrm{ZnO}$.

\begin{tabular}{|c|c|c|c|c|c|c|}
\hline $\begin{array}{l}\text { Synthesis } \\
\text { code }\end{array}$ & $\begin{array}{l}\text { Experimental } \\
\text { conditions } \\
\text { (irradiation time }{ }^{\mathrm{a}} \text {, } \\
\text { temperature, and } \\
\text { microwave power) }\end{array}$ & $\begin{array}{l}\text { Zn precursor, } 15 \mathrm{~mL} \\
1.6 \mathrm{~mol} \mathrm{~L}^{-1}\end{array}$ & $\begin{array}{l}\text { Base, } 4 \mathrm{~mL} \\
3.2 \mathrm{~mol} \mathrm{~L}^{-1}\end{array}$ & Yield, \% & $\begin{array}{l}\text { Average crystallite } \\
\text { size, } \mathrm{nm}\end{array}$ & $\begin{array}{c}\text { Average particle size }{ }^{\mathrm{h}}, \\
\qquad \mu \mathrm{m}\end{array}$ \\
\hline MW-1 & $20 \mathrm{~min}, 80^{\circ} \mathrm{C}, 600 \mathrm{~W}$ & $\mathrm{Zn}\left(\mathrm{NO}_{3}\right)_{2} 6 \mathrm{H}_{2} \mathrm{O}$ & $\mathrm{NaOH}$ & N.A & N.A & N.A \\
\hline MW-2 & $20 \mathrm{~min}, 100^{\circ} \mathrm{C}, 600 \mathrm{~W}$ & $\mathrm{Zn}\left(\mathrm{NO}_{3}\right)_{2} 6 \mathrm{H}_{2} \mathrm{O}$ & $\mathrm{NaOH}$ & N.A & N.A & $\begin{array}{l}0.413\left(\mathrm{~W}^{\mathrm{i}}\right) \\
0.088\left(\mathrm{~L}^{\mathrm{j}}\right)\end{array}$ \\
\hline MW-3 & $20 \mathrm{~min}, 120^{\circ} \mathrm{C}, 600 \mathrm{~W}$ & $\mathrm{Zn}\left(\mathrm{NO}_{3}\right)_{2} 6 \mathrm{H}_{2} \mathrm{O}$ & $\mathrm{NaOH}$ & 93.51 & 8.05 & $\begin{array}{l}1.116(\mathrm{~W}) \\
3.099(\mathrm{~L})\end{array}$ \\
\hline MW-4 & $20 \mathrm{~min}, 140^{\circ} \mathrm{C}, 600 \mathrm{~W}$ & $\mathrm{Zn}\left(\mathrm{NO}_{3}\right)_{2} 6 \mathrm{H}_{2} \mathrm{O}$ & $\mathrm{NaOH}$ & 89.71 & 8.25 & $\begin{array}{c}1.927(\mathrm{~W}) \\
6.512(\mathrm{~L})\end{array}$ \\
\hline$M W-5^{b}$ & $20 \mathrm{~min}, 140^{\circ} \mathrm{C}, 600 \mathrm{~W}$ & $\mathrm{Zn}\left(\mathrm{NO}_{3}\right)_{2} 6 \mathrm{H}_{2} \mathrm{O}$ & $\mathrm{NaOH}$ & 99.31 & 6.41 & $\begin{array}{c}1.534(\mathrm{~W}) \\
3.577(\mathrm{~L})\end{array}$ \\
\hline$M W-6^{c}$ & $20 \mathrm{~min}, 140^{\circ} \mathrm{C}, 600 \mathrm{~W}$ & $\mathrm{Zn}\left(\mathrm{NO}_{3}\right)_{2} 6 \mathrm{H}_{2} \mathrm{O}$ & $\mathrm{NaOH}$ & 87.02 & 6.41 & $\begin{array}{c}0.128(\mathrm{~W}) \\
0.192(\mathrm{~L})\end{array}$ \\
\hline$M W-7^{d}$ & $20 \mathrm{~min}, 140^{\circ} \mathrm{C}, 600 \mathrm{~W}$ & $\mathrm{Zn}\left(\mathrm{NO}_{3}\right)_{2} 6 \mathrm{H}_{2} \mathrm{O}$ & $\mathrm{NaOH}$ & 92.30 & 6.31 & $\begin{array}{l}0.123(\mathrm{~W}) \\
0.059(\mathrm{~L})\end{array}$ \\
\hline$M W-8^{e}$ & $20 \mathrm{~min}, 140^{\circ} \mathrm{C}, 600 \mathrm{~W}$ & $\mathrm{Zn}\left(\mathrm{NO}_{3}\right)_{2} 6 \mathrm{H}_{2} \mathrm{O}$ & $\mathrm{NaOH}$ & 82.72 & 7.53 & $\begin{array}{l}0.394(\mathrm{~W}) \\
0.311(\mathrm{~L})\end{array}$ \\
\hline$M W-9^{f}$ & $20 \mathrm{~min}, 140^{\circ} \mathrm{C}, 600 \mathrm{~W}$ & $\mathrm{Zn}\left(\mathrm{NO}_{3}\right)_{2} 6 \mathrm{H}_{2} \mathrm{O}$ & $\mathrm{NaOH}$ & 89,73 & 8.22 & $\begin{array}{c}1.308(\mathrm{~W}) \\
4.092(\mathrm{~L})\end{array}$ \\
\hline MW-10 & $0 \mathrm{~min}, 140^{\circ} \mathrm{C}, 600 \mathrm{~W}$ & $\mathrm{Zn}\left(\mathrm{NO}_{3}\right)_{2} 6 \mathrm{H}_{2} \mathrm{O}$ & $\mathrm{NaOH}$ & N.A & 8.25 & N.A \\
\hline MW-11 & $5 \mathrm{~min}, 140^{\circ} \mathrm{C}, 600 \mathrm{~W}$ & $\mathrm{Zn}\left(\mathrm{NO}_{3}\right)_{2} 6 \mathrm{H}_{2} \mathrm{O}$ & $\mathrm{NaOH}$ & 91.17 & 8.22 & $\begin{array}{c}1.467(\mathrm{~W}) \\
3.256(\mathrm{~L})\end{array}$ \\
\hline MW-12 & $10 \mathrm{~min}, 140^{\circ} \mathrm{C}, 600 \mathrm{~W}$ & $\mathrm{Zn}\left(\mathrm{NO}_{3}\right)_{2} 6 \mathrm{H}_{2} \mathrm{O}$ & $\mathrm{NaOH}$ & 92.23 & 8.23 & $\begin{array}{c}1.006(\mathrm{~W}) \\
2.493(\mathrm{~L})\end{array}$ \\
\hline MW-13 & $20 \mathrm{~min}, 140^{\circ} \mathrm{C}, 300 \mathrm{~W}$ & $\mathrm{Zn}\left(\mathrm{NO}_{3}\right)_{2} 6 \mathrm{H}_{2} \mathrm{O}$ & $\mathrm{NaOH}$ & 81.40 & 8.26 & $\begin{array}{c}1.487(\mathrm{~W}) \\
3.924(\mathrm{~L})\end{array}$ \\
\hline MW-14 & $20 \mathrm{~min}, 140^{\circ} \mathrm{C}, 1200 \mathrm{~W}$ & $\mathrm{Zn}\left(\mathrm{NO}_{3}\right)_{2} 6 \mathrm{H}_{2} \mathrm{O}$ & $\mathrm{NaOH}$ & 90.35 & 8.40 & $\begin{array}{l}1.351(\mathrm{~W}) \\
3.154(\mathrm{~L})\end{array}$ \\
\hline MW-15 & $20 \mathrm{~min}, 140^{\circ} \mathrm{C}, 600 \mathrm{~W}$ & $\mathrm{Zn}\left(\mathrm{NO}_{3}\right)_{2} 6 \mathrm{H}_{2} \mathrm{O}$ & $\mathrm{KOH}$ & 87.00 & 7.77 & $\begin{array}{c}0.870(\mathrm{~W}) \\
2.375(\mathrm{~L})\end{array}$ \\
\hline MW-16 & $20 \mathrm{~min}, 140^{\circ} \mathrm{C}, 600 \mathrm{~W}$ & $\mathrm{Zn}\left(\mathrm{NO}_{3}\right)_{2} 6 \mathrm{H}_{2} \mathrm{O}$ & $\mathrm{KOH}^{\mathrm{g}}$ & N.A & 7.81 & $\begin{array}{c}0.220(\mathrm{~W}) \\
1.063(\mathrm{~L})\end{array}$ \\
\hline MW-17 & $20 \mathrm{~min}, 140^{\circ} \mathrm{C}, 600 \mathrm{~W}$ & $\mathrm{Zn}\left(\mathrm{NO}_{3}\right)_{2} 6 \mathrm{H}_{2} \mathrm{O}$ & $\mathrm{NH}_{4} \mathrm{OH}$ & N.A & 7.54 & $\begin{array}{c}1.689(\mathrm{~W}) \\
4.673(\mathrm{~L})\end{array}$ \\
\hline MW-18 & $20 \mathrm{~min}, 100^{\circ} \mathrm{C}, 600 \mathrm{~W}$ & $\mathrm{Zn}\left(\mathrm{CH}_{3} \mathrm{COO}\right)_{2} 2 \mathrm{H}_{2} \mathrm{O}$ & $\mathrm{NaOH}$ & N.A & 8.05 & $\begin{array}{l}3.716(\mathrm{~W}) \\
3.662(\mathrm{~L})\end{array}$ \\
\hline MW-19 & $20 \mathrm{~min}, 120^{\circ} \mathrm{C}, 600 \mathrm{~W}$ & $\mathrm{Zn}\left(\mathrm{CH}_{3} \mathrm{COO}\right)_{2} 2 \mathrm{H}_{2} \mathrm{O}$ & $\mathrm{NaOH}$ & N.A & 7.97 & $\begin{array}{l}3.128(\mathrm{~W}) \\
3.951(\mathrm{~L})\end{array}$ \\
\hline MW-20 & $20 \mathrm{~min}, 140^{\circ} \mathrm{C}, 600 \mathrm{~W}$ & $\mathrm{Zn}\left(\mathrm{CH}_{3} \mathrm{COO}\right)_{2} 2 \mathrm{H}_{2} \mathrm{O}$ & $\mathrm{NaOH}$ & N.A & 8.15 & $\begin{array}{l}1.656(\mathrm{~W}) \\
1.735(\mathrm{~L})\end{array}$ \\
\hline MW-21 & $20 \mathrm{~min}, 140^{\circ} \mathrm{C}, 600 \mathrm{~W}$ & $\mathrm{ZnCl}_{2}$ & $\mathrm{NaOH}$ & N.A & N.A & N.A \\
\hline
\end{tabular}

${ }^{a}$ An initial $10 \mathrm{~min}$ period required to reach the target temperature must be considered in all cases.

${ }^{\mathrm{b}}$ Solid product was isolated by centrifugation. The product was not washed.

${ }^{\mathrm{c}}$ Change in the addition order.

${ }^{\mathrm{d}} 0.24 \mathrm{~g}$ of sodium di-2-ethylhexyl-sulfosuccinate dissolved in water were added before base addition.

${ }^{\mathrm{e}} 0.50 \mathrm{~g}$ of sodium di-2-ethylhexyl-sulfosuccinate dissolved in water were added before base addition.

${ }^{\mathrm{f}} 1 \mathrm{~g}$ of ethylene glycol dissolved in water was added before base addition.

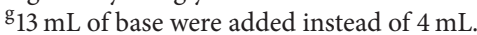

${ }^{\mathrm{h}}$ Calculated from SEM images employing ImageJ Software.

${ }^{\mathrm{i}}$ Average width of the rod-like particles.

${ }^{\mathrm{j}}$ Average length of the rod-like particles.

N.A: not available. 
$2 \theta=31.8,34.3$, and $36.5^{\circ}$, which correspond to the (100), (002), and (101) planes of wurtzite $\mathrm{ZnO}$, respectively. FESEM images show an almost homogeneous morphological distribution at a set reaction temperature of $140^{\circ} \mathrm{C}$. In this case most $\mathrm{ZnO}$ particles were formed as bihexagonal rods which were probably stacked from sheets with a starting growth from both sides. Additionally, a low population of $\mathrm{ZnO}$ particles with a more complex three-dimensional structure can be observed (MW-4, Figure 1) where a radial growth from a center seems to be favored yielding nanodandelions-like morphologies [16]. On the other hand, when the precursors are irradiated at $120^{\circ} \mathrm{C}(\mathrm{MW}-3$, Figure 1), the FE-SEM images show that, while some particles are formed, there is still a heterogeneous background. A possible explanation for this behavior can be linked to the existence of a greater irradiation to achieve a higher temperature, which increases the polarization of the system by producing a more orderly system that favors the nucleation and growth of the $\mathrm{ZnO}$ nanoparticles as was also described by other authors [18].

On the other hand, FTIR studies (Figure 1) show the characteristic vibrations of $\mathrm{ZnO}$ in the product obtained at $140^{\circ} \mathrm{C}$. In all the cases the FTIR spectrums show absorption bands centered at about 3430 and $2344 \mathrm{~cm}^{-1}$, which can be assigned to the $\mathrm{O}-\mathrm{H}$ stretching vibrations, and bands centered at 1630 and $1384 \mathrm{~cm}^{-1}$ that correspond to the asymmetric and symmetric $\mathrm{C}=\mathrm{O}$ stretching modes $\left(\mathrm{CO}_{2}\right.$ modes $)$. At low wavenumbers there can be observed two peaks located at approximately 420 and $512 \mathrm{~cm}^{-1}$, corresponding to the $\mathrm{ZnO}$ rod like-nanostructures [20, 21].

3.2. Precursors Effect. Three different precursors were employed to synthetize $\mathrm{ZnO}$ (temperature $140^{\circ} \mathrm{C}$; power $600 \mathrm{~W}$ ): $\mathrm{Zn}\left(\mathrm{NO}_{3}\right)_{2} \cdot 6 \mathrm{H}_{2} \mathrm{O}(\mathrm{MW}-4), \mathrm{Zn}\left(\mathrm{CH}_{3} \mathrm{COO}\right)_{2} \cdot 2 \mathrm{H}_{2} \mathrm{O}(\mathrm{MW}-20)$, and $\mathrm{ZnCl}_{2}$ (MW-21). Figure 2 shows the corresponding morphologies as well as XRD analysis for these samples.

As it can be observed from Figure 2, XRD analysis shows that when $\mathrm{Zn}\left(\mathrm{NO}_{3}\right)_{2}$ and $\mathrm{Zn}\left(\mathrm{CH}_{3} \mathrm{COO}\right)_{2}$ are the precursor salts, all the diffraction peaks match those of the wurtzite $\mathrm{ZnO}$ as it was described above. The morphological distribution is homogeneous in both cases, being in the first case particles with a bihexagonal rod-like structure of about $6 \mu \mathrm{m}$ long and $2 \mu \mathrm{m}$ wide; meanwhile in the second case the morphology is of the hexagonal prismatic type, and the average particle size is of about 3-4 $\mathrm{m}$ long and $1 \mu$ wide. In these both systems the larger particles observed could be grown from small primary particles through an oriented attachment process in which the adjacent nanoparticles are self-assembled by sharing a common crystallographic orientation and docking of these particles at a planar interface.

On the contrary, when $\mathrm{ZnCl}_{2}$ is used as the precursor salt, the corresponding diffractogram shows many signals attributed to precursor reagents and unknown impurities, and a heterogeneous and non-well-defined morphology and a broad particle size distribution can be observed.

Taking into account that the growth of large crystals depends on the counteranion as it was previously described [22], the difference in the morphology of the three analyzed systems can be attributed to the fact that, in the case of the halide anion, it adsorbs more strongly on surfaces than acetate ions and nitrate ions which exhibits very weak surface interaction. As the adsorption on surfaces increases, the growth process decreases conducting particles with lower sizes as it can be observed in Figure 2 where the size of the synthesized $\mathrm{ZnO}$ particles decreases in the following order: $\mathrm{NO}_{3}^{-}>\mathrm{CH}_{3} \mathrm{COO}^{-}>\mathrm{Cl}^{-}$.

This behavior can also be confirmed by the fact that nitrate anion is a noncoordinative ligand, so that the hexagonal wurtzite prefers growing in the $c$ axis (0001 plane); meanwhile in the case of acetate ion it is a chelating ligand that allows a better control on the $\mathrm{ZnO}$ particle development yielding particles with lower particle size.

On the other hand and for the case of $\mathrm{Zn}\left(\mathrm{NO}_{3}\right)_{2}$, the order of reagents addition during the synthesis of nano$\mathrm{ZnO}$ was analyzed; when a solution of $\mathrm{Zn}\left(\mathrm{NO}_{3}\right)_{2}$ precursor was added dropwise over $\mathrm{NaOH}$ solution (basic route), different morphologies (short rows, etc.) were obtained in the final product (MW-6) with a wide particle size distribution and arranged in the form of agglomerates (Figure 3). This behavior can be explained attending to the following reaction mechanism. The first step in the synthetic reaction, irrespective of the route employed (acidic or basic), corresponds to the formation of a colloidal system:

$$
\mathrm{Zn}^{2+}(\mathrm{aq})+2 \mathrm{OH}^{-}(\mathrm{aq}) \longrightarrow \mathrm{Zn}(\mathrm{OH})_{2}(\mathrm{~s}) \downarrow
$$

The zinc cations are known to react with hydroxide anions to form stable $\mathrm{Zn}(\mathrm{OH})_{4}{ }^{2-}$ complexes, which could act as the growing unit of $\mathrm{ZnO}$ nanostructures [23, 24]. Therefore, the growth mechanism can be considered as follows when the synthesis is carried out through the acidic route:

$$
\begin{gathered}
\mathrm{Zn}(\mathrm{OH})_{2}(\mathrm{~s})+2 \mathrm{H}_{2} \mathrm{O} \stackrel{\text { Microwave }}{\longrightarrow} \mathrm{Zn}(\mathrm{OH})_{4}{ }^{2-}+2 \mathrm{H}^{+} \\
\stackrel{\text { Microwave }}{\longrightarrow} \mathrm{ZnO}+3 \mathrm{H}_{2} \mathrm{O}
\end{gathered}
$$

When the addition is made in such a way that $\mathrm{OH}^{-}$is aggregated over the $\mathrm{Zn}^{+2}$ solution, reaction symbolized by (2) takes place, and the formation of growing units during the irradiation stage is favored as it is symbolized in (3). In this sense, $\mathrm{Zn}(\mathrm{OH})_{4}{ }^{2-}$ species are generated under microwave effect, and it is well known that growing species can be polarized [18] allowing a controlled and directed growth of the particles.

On the other hand, if $\mathrm{Zn}^{+2}$ is added slowly over the $\mathrm{OH}^{-}$ solution as in the case of MW-6, the growing units can be formed rapidly, and the following reaction can occur before irradiation:

$$
\mathrm{Zn}(\mathrm{OH})_{2}(\mathrm{~s})+2 \mathrm{OH}^{-} \longleftrightarrow \mathrm{Zn}(\mathrm{OH})_{4}{ }^{2-}
$$

The $\mathrm{Zn}(\mathrm{OH})_{4}{ }^{2-}$ species formed have no polarization by microwave radiation, and the growth of the particles is in a random way.

3.3. Washing Solvent Effect. There has been described in the literature the effect of different solvents (ethanol, water, or 

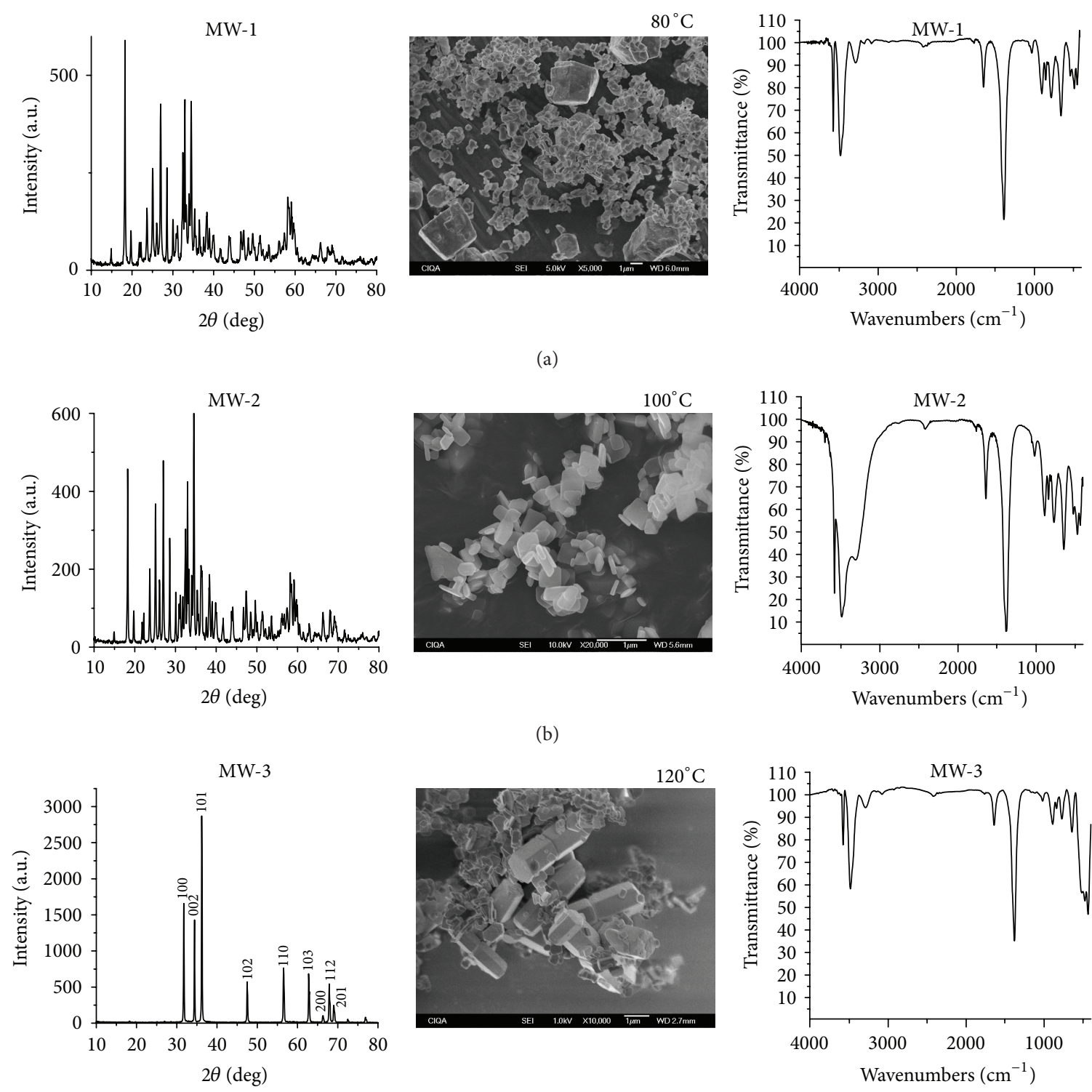

(b)
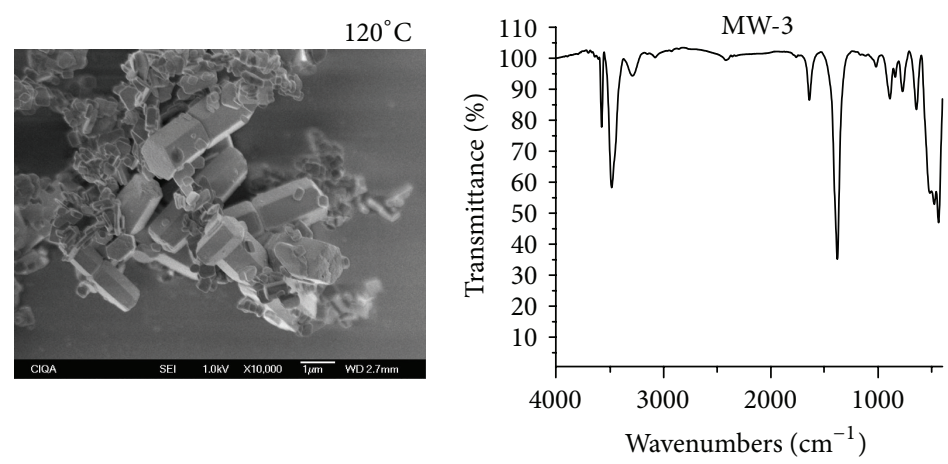

(c)
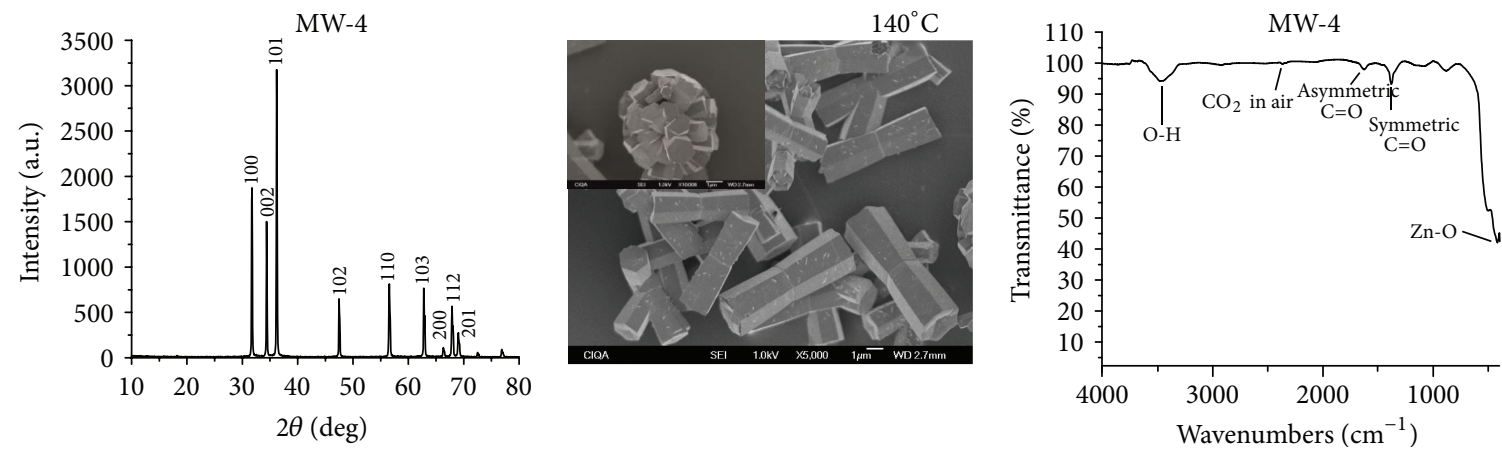

(d)

FIGURE 1: Temperature effect during microwave synthesis of $\mathrm{ZnO}$ on its morphological development. 

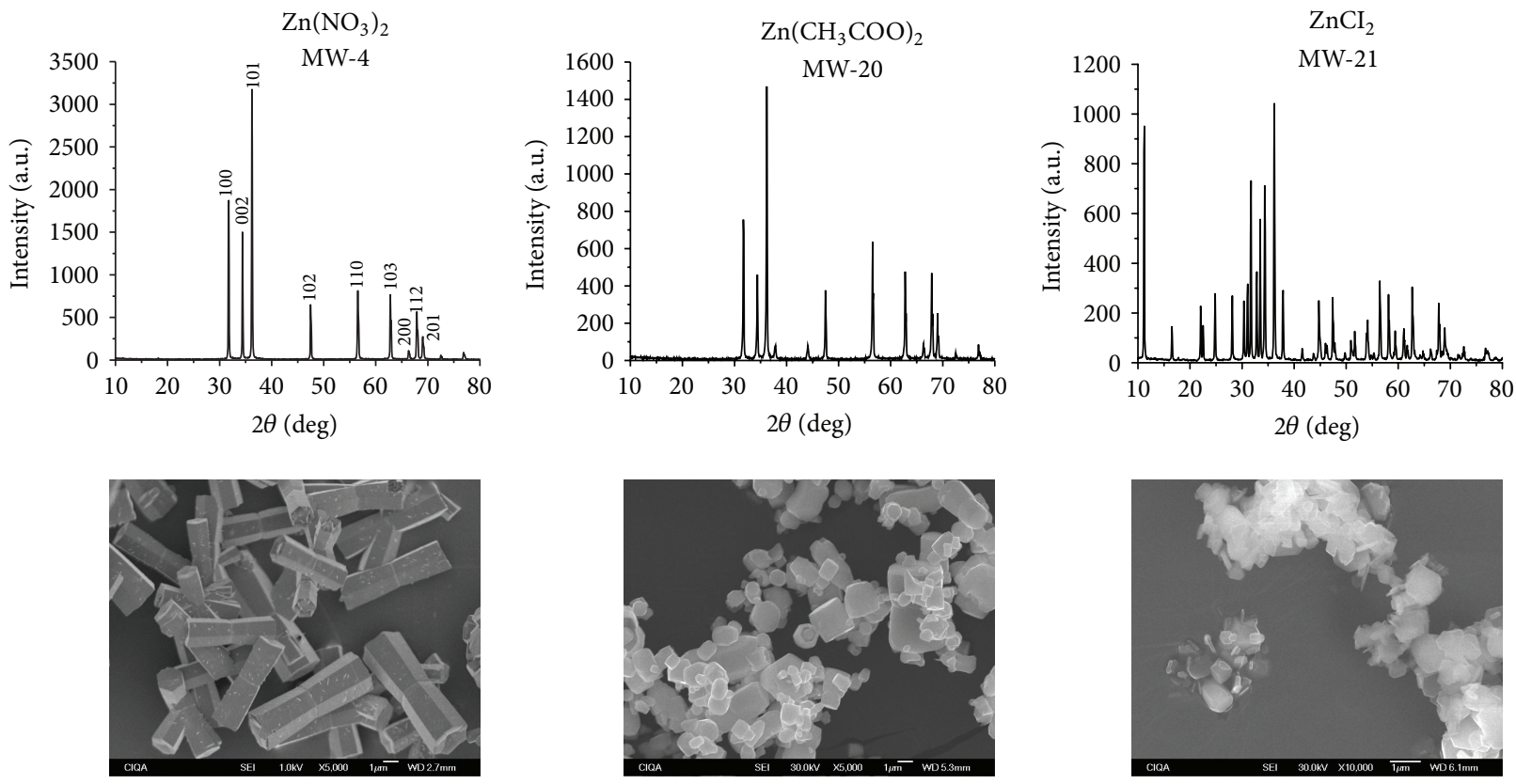

(a)

(b)

(c)

FIGURE 2: Effect of precursor salt during microwave synthesis of $\mathrm{ZnO}$ on its morphological development, at $140^{\circ} \mathrm{C}$ and $600 \mathrm{~W}$.
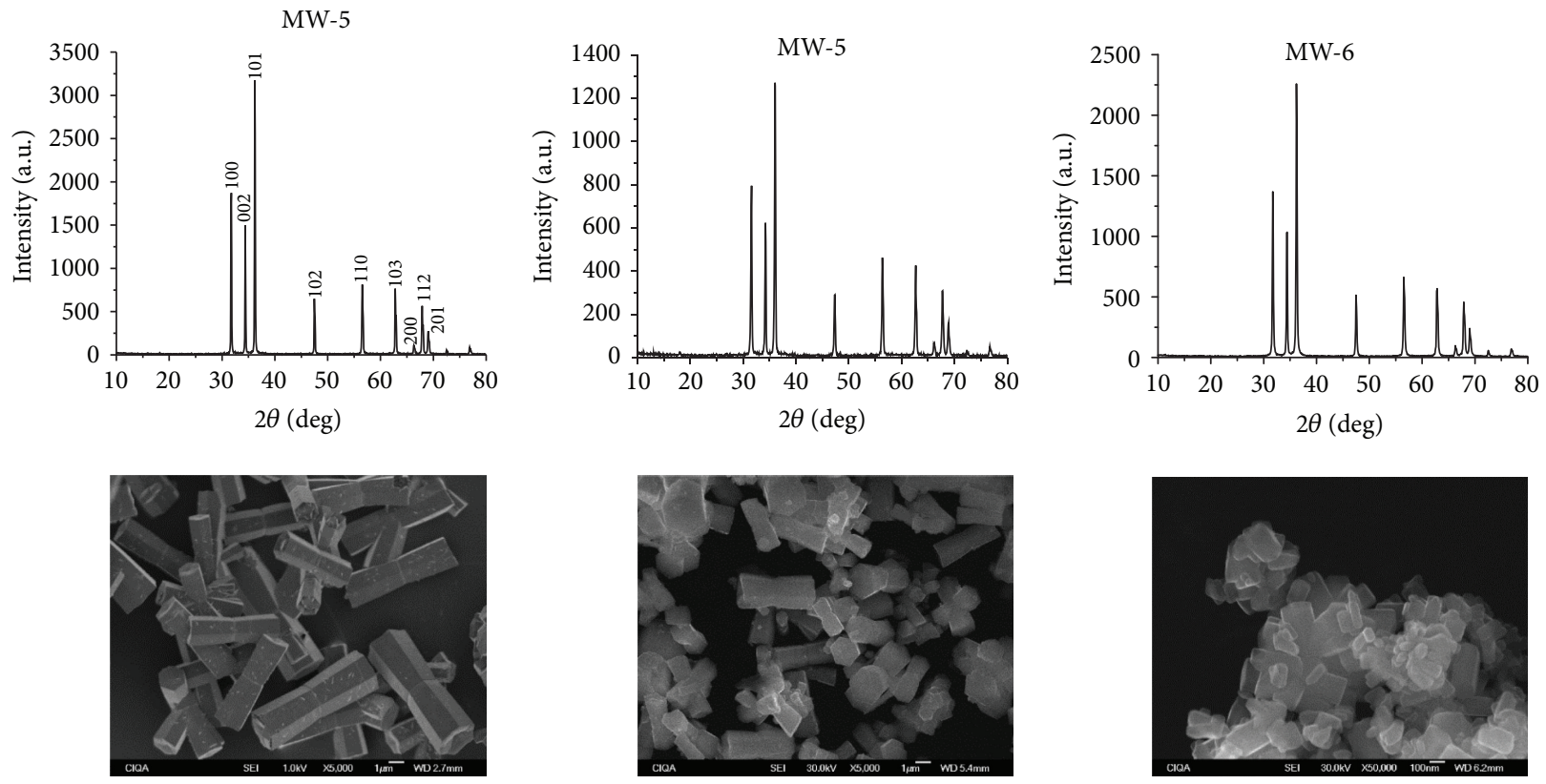

(a)

(b)

(c)

FIGURE 3: Isolation and precursors order addition effects on $\mathrm{ZnO}$ final morphology.

both) used during the washing step on the morphological parameters of the nano- $\mathrm{ZnO}$ [25], and it was evidenced that they can affect the morphological characteristics of the final product damaging the surface of $\mathrm{ZnO}$, depending on the solvent used and on its polarity and vapor pressure. Attending to these results it was decided to carry out a synthesis where the isolation of nano- $\mathrm{ZnO}$ was made by centrifugation (10 min at $10000 \mathrm{rpm}$; MW-5) without previous washes; instead water is a preferable solvent to be used for $\mathrm{ZnO}$ [25]. $\mathrm{XRD}$ analysis for the former case, it means centrifugation without further purification, shows the wurtzite hexagonal $\mathrm{ZnO}$ characteristics (Figure 3 ). From the images obtained by 

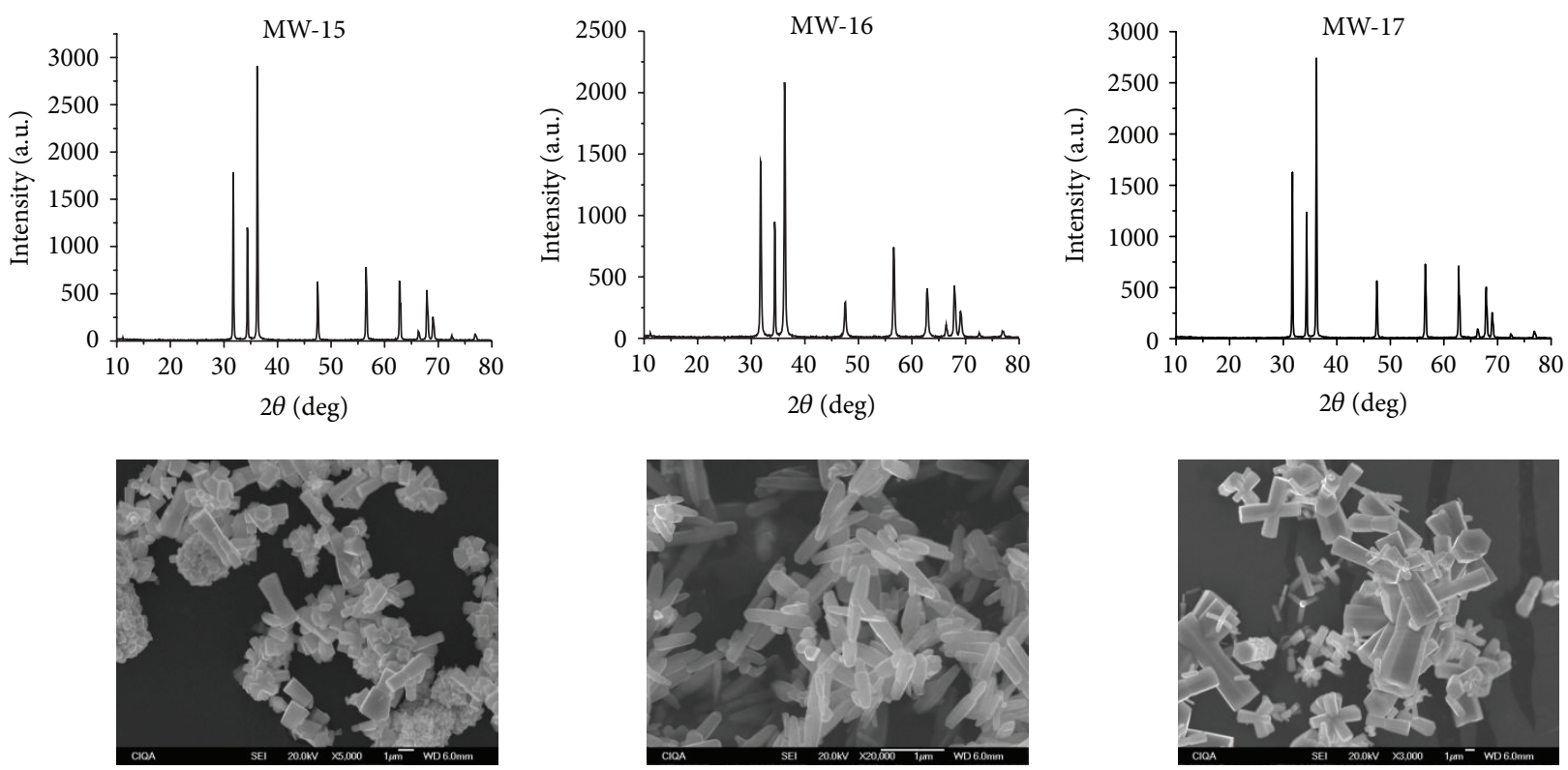

(a)

(b)

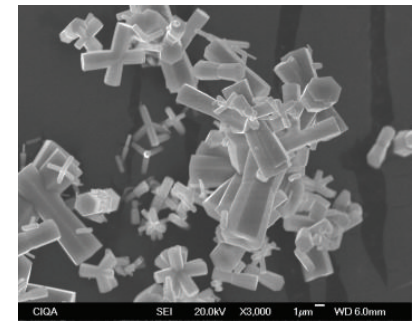

(c)

Figure 4: Base effect in microwave assisted $\mathrm{ZnO}$ synthesis. (a) $\mathrm{KOH}$, (b) $\mathrm{KOH} 13 \mathrm{~mL}$, and (c) $\mathrm{NH}_{4} \mathrm{OH}$.

FE-SEM a more dispersed system from both, morphological and size distribution aspects (Figure 3), can be observed with a less resolution on the lattices of the bihexagonal rod-like structure.

3.4. Precursor Base Effect. The results presented up to this point have been obtained using $\mathrm{NaOH}$ as the precursor base. However, $\mathrm{KOH}(\mathrm{MW}-15)$ and $\mathrm{NH}_{4} \mathrm{OH}(\mathrm{MW}-17)$ have also been used under the same experimental conditions in order to analyze their effect on the morphological characteristics of the nanoparticles produced. In the case of using $\mathrm{KOH}$ two populations of well-defined morphologies can be observed (Figure 4(a)); one of them is similar to that obtained when $\mathrm{NaOH}$ is used as the precursor base (Figure 1, MW-4), in the form of bihexagonal rods, and there is another population of particles in the form of agglomerates which are constituted by small particles. When $\mathrm{NH}_{4} \mathrm{OH}$ is used as the base, two morphologies can be clearly observed; the characteristic hexagonal rods previously described in the case of $\mathrm{NaOH}$ and $\mathrm{KOH}$ and other one where two- or three-dimensional growths are favored (Figure 4(c)). In this last case the growth is favored radially and in different directions yielding threedimensional complex particles, similar to the dandelions particles obtained by Huang et al. [16]. The changes in morphology are attributed to the different degrees of electrostatic effects of the hydrated ion $\left(\mathrm{Na}^{+}, \mathrm{K}^{+}\right.$, or $\left.\mathrm{NH}_{4}^{+}\right)$which can act on the surface of the growing crystals causing different growth on their surfaces. Therefore, the size of hydrated ions $\left(\mathrm{K}^{+} \cong \mathrm{NH}_{4}{ }^{+}<\mathrm{Na}^{+}\right)$and their charge are important factors in this approach.

In this sense, when the more bulky $\mathrm{Na}^{+}$is present, the $\mathrm{Zn}^{+2}$ is preferably adsorbed on the $0001^{+/-}$planes so that the crystals show oriented growth along these directions. On the contrary, when $\mathrm{K}^{+}$is the counterion, there is a competition between $\mathrm{K}^{+}$and $\mathrm{Zn}^{+2}$, and $\mathrm{K}^{+}$inhibited the adsorption of $\mathrm{Zn}^{+2}$ on the $0001^{+/-}$planes, so $\mathrm{Zn}^{+2}$ must be adsorbed not only on the $0001^{+/-}$planes but also onto the other six planes yielding particles with shorter length and higher diameter, in a similar way as the behavior described by Nejati et al. [26].

3.5. Stoichiometry Effect. The stoichiometry relation between $\mathrm{Zn}^{+2}$ and $\mathrm{OH}^{-}$was also studied, and instead of adding the amount of base described in the synthesis $\left(\mathrm{Zn}^{+2} / \mathrm{OH}^{-}=\right.$ 1.87/1) (Section 2.1), that allows carrying out the reaction at $\mathrm{pH}$ of $5.8,13 \mathrm{~mL}$ of $\mathrm{KOH}\left(\mathrm{Zn}^{+2} / \mathrm{OH}^{-}=1 / 1.73\right)(\mathrm{MW}-16)$ were added, and a $\mathrm{pH}$ of 10.8 was reached. This modification in $\mathrm{OH}^{-}$concentration has been directly reflected in a morphological change of the particles obtained (Figure 4(b)). This effect is attributed to a different reaction mechanism in the generation of $\mathrm{ZnO}$ particles.

If an excess of $\mathrm{OH}^{-}$is added (like in $\mathrm{MW}-16$ synthesis) to the aqueous solution, the precipitated $\mathrm{Zn}(\mathrm{OH})_{2}(\mathrm{~s})$ species formed in (2) would dissolve back into the alkali solution to form the initial ions [27], and, after certain reaction time during the stirring period, the reaction symbolized by (4) can occur before irradiation with the formation of $\mathrm{Zn}(\mathrm{OH})_{4}{ }^{2-}$ complexes. As $\mathrm{KOH}$ concentration increases, the $\mathrm{Zn}(\mathrm{OH})_{4}{ }^{2-}$ complexes are surrounded by a large amount of $\mathrm{OH}^{-}$so that the differences in the observed morphologies (Figures $4(\mathrm{a})$ and $4(\mathrm{~b}))$ can be attributed to the different stages where growth unit can be formed and to the initial zinc species and their environment in the reactor as it was demonstrated by $\mathrm{Xu}$ et al. in the case of $\mathrm{ZnO}$ synthesis via a hydrothermal method [28]. 
3.6. Power and Irradiation Time Effect. In order to analyze the microwave irradiation system controllable variables, such as power and irradiation time on the produced $\mathrm{ZnO}$ morphology, some experiments were carried out under the same experimental conditions but with different irradiation times: only initial ramp $(10 \mathrm{~min})(\mathrm{MW}-10)$ to reach the target temperature $\left(140^{\circ} \mathrm{C}\right)$, and 5,10 , and 20 min after reaching the desirable temperature (Table 1; MW-11, MW-12, and MW-4, resp.). By XRD and IR techniques it could be observed that only in the case of using the initial ramp (MW-10) there is evidence of signals indicating the presence of impurities in the final product. In the other three cases (MW-11, $\mathrm{MW}-12$, and MW-4) only wurtzite hexagonal signals and $\mathrm{ZnO}$ characteristics vibrations are present. In Figure 5 the morphology evolution of $\mathrm{ZnO}$ nanoparticles with irradiation time can be observed where an increase in this parameter generates more defined structures and a final system with a more homogeneous particle size and morphology distribution as a consequence of more time for the 0001 plane to growth.

On the other hand, when the effect of power microwave irradiation was analyzed (samples MW-13, MW-4, and MW14 for 300, 600, and $1200 \mathrm{~W}$, resp., Table 1) (Figure 6), it was observed that the formation of aggregates is favored as the microwave power increases. As microwave power increases, there is an increase in the mixture aqueous solution temperature enhancing the tendency of the $\mathrm{ZnO}$ nuclei to aggregate, in a similar way to that described by $\mathrm{Al}-$ Gaashani et al. [18]. Moreover, when the power is set to $1200 \mathrm{~W}$ (Figure 6(c)), the generation of agglomerates makes the system not homogeneous and not well dispersed like the one obtained at $600 \mathrm{~W}$ (Figure 6(b)).

3.7. Additives Effect. It is well known that the use of additives leads to changes in $\mathrm{ZnO}$ crystal growth [29]. In this work the effect of the addition of an anionic surfactant (sodium di-2ethylhexyl-sulfosuccinate (AOT)) and a dispersant (ethylene glycol) on $\mathrm{ZnO}$ particles obtained by microwave synthetic method was evaluated. In these experiments the syntheses were carried out in the same way as it was previously described by dissolving $\mathrm{Zn}^{+2}$ in an additive (AOT or ethylene glycol) aqueous solution.

As it can be inferred from Figure 7(a), when $1 \mathrm{~g}(16 \mathrm{mmol})$ of ethylene glycol was added, (MW-9) to the reaction media, there were no significant changes neither in the morphology nor in the size of the obtained $\mathrm{ZnO}$ particles in comparison with the product obtained in the absence of any additive (MW-4).

On the contrary, when AOT surfactant was added, important changes could be observed. With $0.24 \mathrm{~g}$ of AOT $(0.5 \mathrm{mmol})(\mathrm{MW}-7)$ the particles show a different morphology (Figure 7(b)) in the sense that there is a lower growth in $c$ axis ([001] direction), so smaller hexagonal prismatic particles are formed with sizes in the interval of 60-80 $\mathrm{nm}$ in diameter and length between 90 and $110 \mathrm{~nm}$ when compared with MW-4. Similar results were obtained when $0.5 \mathrm{~g}$ of AOT $(1.1 \mathrm{mmol})$ were added $(\mathrm{MW}-8)$. In this case characteristic vibrations of surfactant could be observed by FTIR due to surfactant traces are still present after washes made with ethanol and deionized water.

The previous results can be attributed to the fact that AOT can be acting as an external factor that can control the growth rate of various faces of the crystals, due to the adsorption of the counterions on the negatively charged surfaces (precursor $\mathrm{Zn}(\mathrm{OH})_{4}{ }^{2-}$ ) reducing the surface energy of the specific crystal faces. This behavior can lead to the control of the crystal growth while retaining in some way the morphology.

3.8. Optical Properties. Having in mind that the absorption of colloidal system depends on the particle size and shape [30], absorption spectra of some synthetized $\mathrm{ZnO}$ nanoparticles were obtained. As it can be observed from Figure 8, particles with size higher than $500 \mathrm{~nm}$ do not show important absorption band, and no maximum can be detected in the absorbance curves (MW-4, MW-15, MW-17, and MW-20). However, when surfactant AOT is added to the reaction media and smaller particles are produced (particles size $<100 \mathrm{~nm}$ ), a significant increase in UV absorption and a well-defined maximum at $374 \mathrm{~nm}$ can be observed. This absorption is caused by two factors; the first one is due to the excitation of the electrons from the valence band to the conduction band when they are irradiated with UV light, which causes the absorption of UV radiation. The second is light scatter; the particle size of a colloidal solution within the wavelength of UV light results in light scattering, which also causes the absorption.

\section{Conclusions}

A simple and effective microwave assisted aqueous solution method has been used to synthetize $\mathrm{ZnO}$ with high crystallinity and purity when $\mathrm{Zn}\left(\mathrm{NO}_{3}\right)_{2}$ is used as precursor reagent. In addition, several parameters have been evaluated in order to analyze their effects on the $\mathrm{ZnO}$ nanoparticles obtained. An increase from $80^{\circ} \mathrm{C}$ to $140^{\circ} \mathrm{C}$ in set reaction temperature allowed to obtain a system with high purity and homogeneous in size and shape. On the other hand, three different $\mathrm{Zn}^{+2}$ precursors were employed to synthetize the nanoparticles: $\mathrm{Zn}\left(\mathrm{NO}_{3}\right)_{2} \cdot 6 \mathrm{H}_{2} \mathrm{O}, \mathrm{Zn}\left(\mathrm{CH}_{3} \mathrm{COO}\right)_{2} \cdot 2 \mathrm{H}_{2} \mathrm{O}$, and $\mathrm{ZnCl}_{2}$. It was observed that, as the adsorption of counteranions on surfaces increases, the synthesized $\mathrm{ZnO}$ particles sizes decrease in the following order: $\mathrm{NO}_{3}{ }^{-}>\mathrm{CH}_{3} \mathrm{COO}^{-}>\mathrm{Cl}^{-}$.

When different $\mathrm{OH}^{-}$precursors were employed $(\mathrm{NaOH}$, $\mathrm{KOH}$, and $\mathrm{NH} 4 \mathrm{OH}$ ), some changes were observed in the morphological characteristics of the synthesized $\mathrm{ZnO}$. If $\mathrm{NH}_{4} \mathrm{OH}$ is used as the base, two morphologies were found: the hexagonal rods described in the case of $\mathrm{NaOH}$ and $\mathrm{KOH}$ and other ones where two- or three-dimensional growths are favored. The final reaction $\mathrm{pH}$ can be mentioned as another important variable that causes significant changes on the morphology of the final product.

An increase in irradiation time generates more defined structures and a final system with a more homogeneous particle size and morphology distribution as a consequence of more time for the $c$ direction to growth. Furthermore, it 


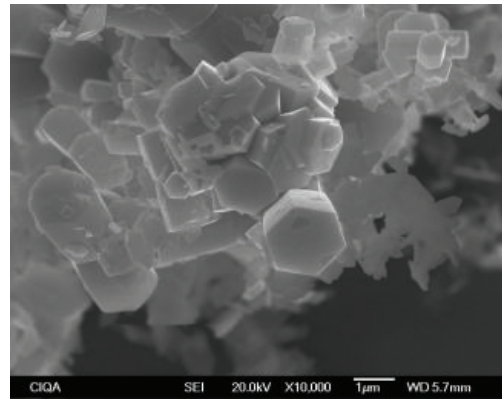

(a)

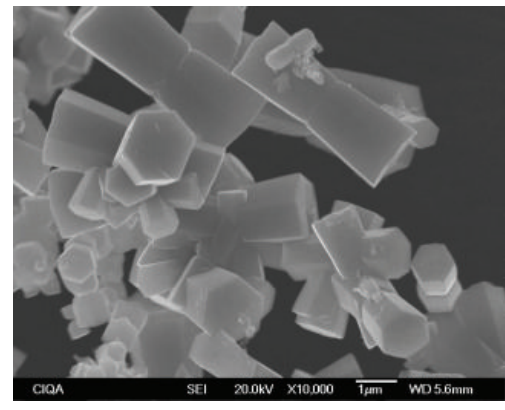

(b)

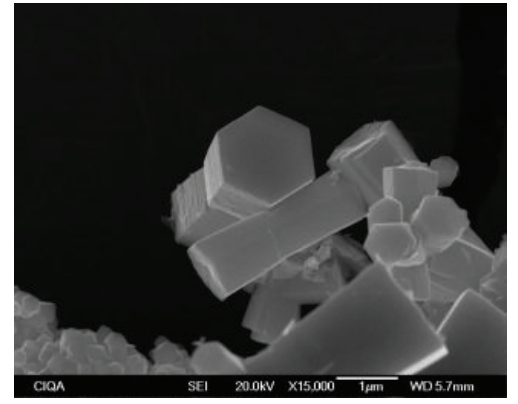

(c)

Figure 5: FE-SEM images of $\mathrm{ZnO}$ obtained at different irradiation times: (a) only initial temperature ramp, (b) $5 \mathrm{~min}$ at $140^{\circ} \mathrm{C}$, and (c) $10 \mathrm{~min}$ at $140^{\circ} \mathrm{C}$.

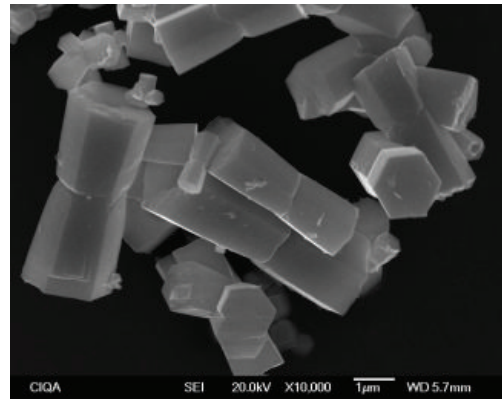

(a)

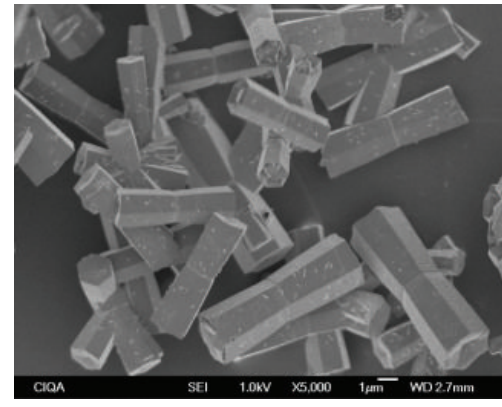

(b)

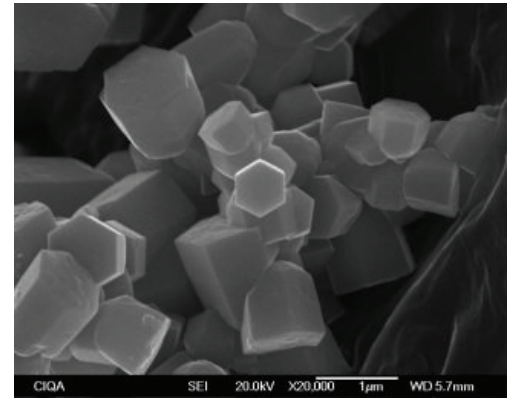

(c)

FIGURE 6: FE-SEM images of $\mathrm{ZnO}$ obtained at different irradiation powers at $140^{\circ} \mathrm{C}$ : (a) $300 \mathrm{~W}$, (b) $600 \mathrm{~W}$, and (c) $1200 \mathrm{~W}$.

was observed that the formation of aggregates is favored as the microwave power increases.

The addition of an anionic surfactant (AOT) to the reaction media allowed the synthesis of smaller particles and a significant increase in UV absorption, and a well-defined maximum at $374 \mathrm{~nm}$ was observed.

As final conclusions it can be enounced that to obtain a very pure phase of $\mathrm{ZnO}$ of high density, employing microwave as energy source, it is recommended to use $\mathrm{Zn}\left(\mathrm{NO}_{3}\right)_{2}$ as precursor.

\section{Acknowledgments}

The authors would like to thank Miriam Lozano and Jesús Angel Cepeda Garza for their contribution on the characterization of the $\mathrm{ZnO}$ nanoparticles by FE-SEM. Also, the authors wish to thank the Mexican National Council for Science and Technology (CONACYT) for its financial support for the realization of this study through a postdoctoral fellowship for Gastón P. Barreto, Ph.D. (CB-2008-01 Project no. 101934).

\section{References}

[1] L. Wang and M. Muhammed, "Synthesis of zinc oxide nanoparticles with controlled morphology," Journal of Materials Chemistry, vol. 9, no. 11, pp. 2871-2878, 1999.
[2] R. Hong, T. Pan, J. Qian, and H. Li, "Synthesis and surface modification of $\mathrm{ZnO}$ nanoparticles," Chemical Engineering Journal, vol. 119, no. 2-3, pp. 71-81, 2006.

[3] F. Paraguay, W. Estrada, D. R. Acosta, E. Andrade, and M. Miki-Yoshida, "Growth, structure and optical characterization of high quality $\mathrm{ZnO}$ thin films obtained by spray pyrolysis," Thin Solid Films, vol. 350, no. 1, pp. 192-202, 1999.

[4] T. Tani, L. Mädler, and S. E. Pratsinis, "Homogeneous ZnO nanoparticles by flame spray pyrolysis," Journal of Nanoparticle Research, vol. 4, no. 4, pp. 337-343, 2002.

[5] J. Wang and L. Gao, "Wet chemical synthesis of ultralong and straight single-crystalline $\mathrm{ZnO}$ nanowires and their excellent UV emission properties," Journal of Materials Chemistry, vol. 13, no. 10, pp. 2551-2554, 2003.

[6] B. Liu and H. C. Zeng, "Hydrothermal synthesis of $\mathrm{ZnO}$ nanorods in the diameter regime of $50 \mathrm{~nm}$," Journal of the American Chemical Society, vol. 125, no. 15, pp. 4430-4431, 2003.

[7] U. Pal and P. Santiago, "Controlling the morphology of $\mathrm{ZnO}$ nanostructures in a low-temperature hydrothermal process," Journal of Physical Chemistry B, vol. 109, no. 32, pp. 15317-15321, 2005.

[8] L. Spanhel and M. A. Anderson, "Semiconductor clusters in the sol-gel process: quantized aggregation, gelation, and crystal growth in concentrated $\mathrm{ZnO}$ colloids," Journal of the American Chemical Society, vol. 113, no. 8, pp. 2826-2833, 1991.

[9] M. Ristić, S. Musić, M. Ivanda, and S. Popović, "Sol-gel synthesis and characterization of nanocrystalline $\mathrm{ZnO}$ powders," Journal of Alloys and Compounds, vol. 397, no. 1-2, pp. L1-L4, 2005. 

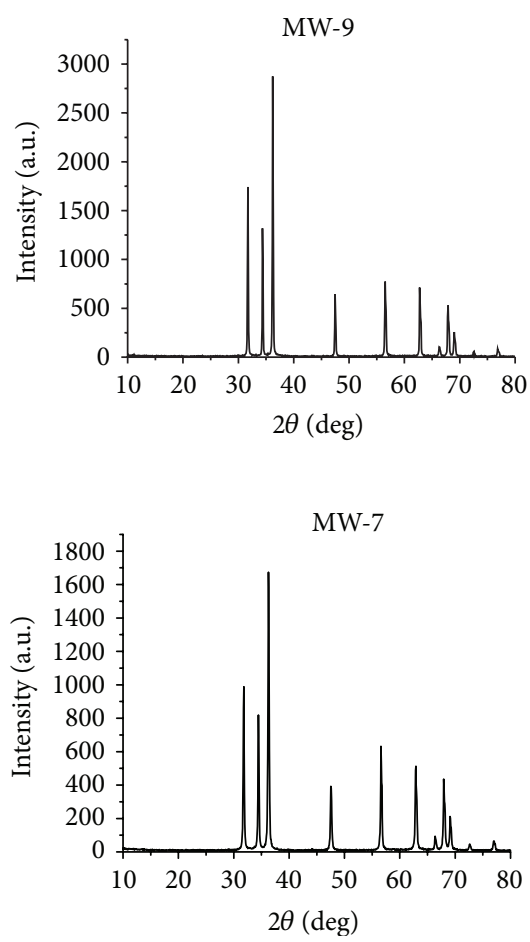
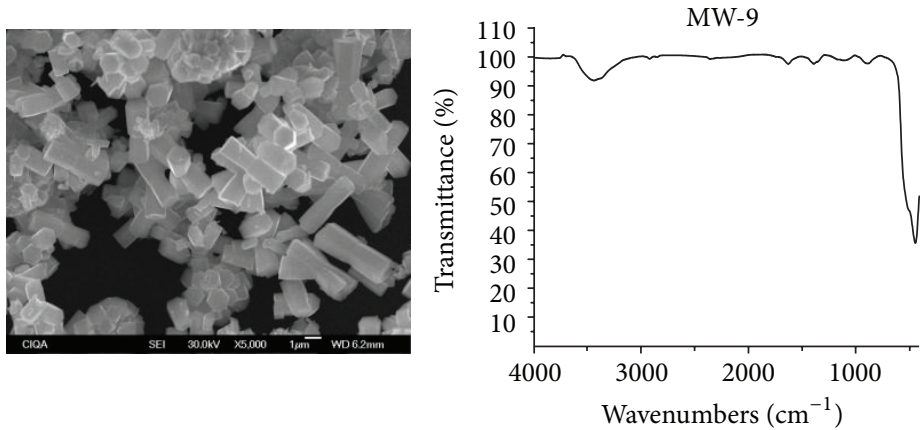

(a)

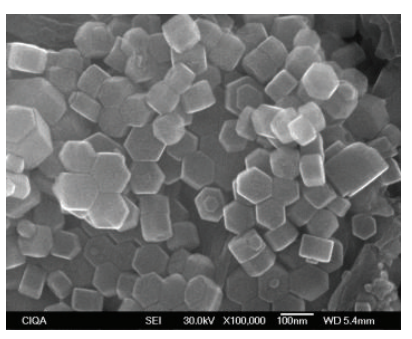

(b)

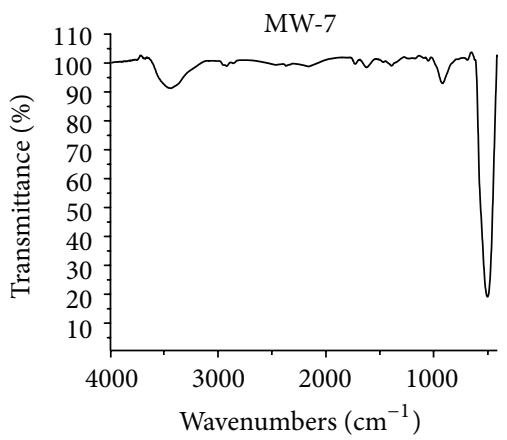

FIGURE 7: XRD, FE-SEM, and FTIR characterization of ZnO synthetized with different additives: (a) $1 \mathrm{~g}$ ethylene glycol, (b) $0.24 \mathrm{~g}$ AOT, and (c) $0.5 \mathrm{~g}$ AOT (experimental conditions: $140^{\circ} \mathrm{C}, 20 \mathrm{~min}$, and $600 \mathrm{~W}$ ).

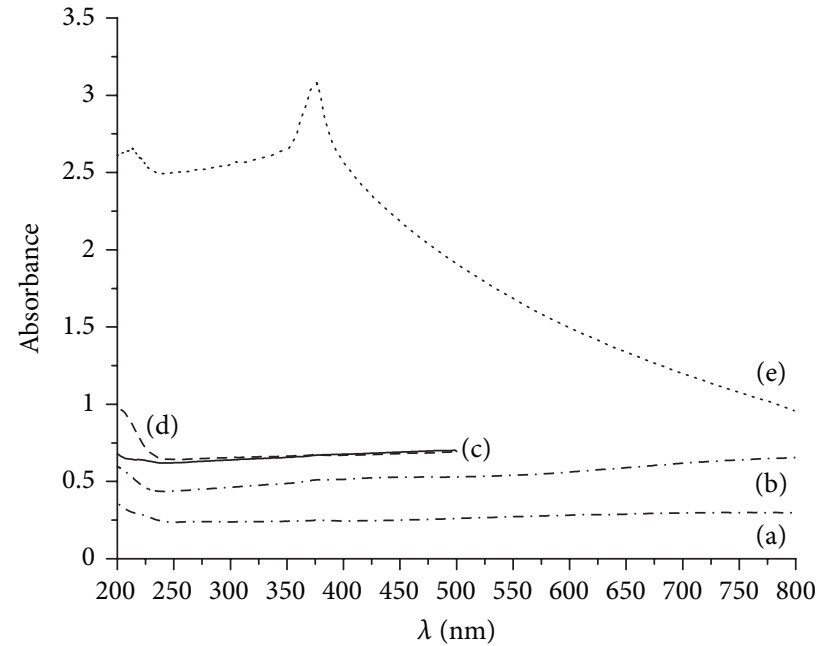

FIGURE 8: UV-Vis spectra of $\mathrm{ZnO}$ nanoparticles dispersed in water. (a) MW-17, (b) MW-15, (c) MW-20, (d) MW-4, and (e) MW-7.

[10] H. M. Cheng, H. C. Hsu, S. L. Chen et al., "Efficient UV photoluminescence from monodispersed secondary $\mathrm{ZnO}$ colloidal spheres synthesized by sol-gel method," Journal of Crystal Growth, vol. 277, no. 1-4, pp. 192-199, 2005.

[11] Y. Y. Tay, S. Li, F. Boey, Y. H. Cheng, and M. H. Liang, "Growth mechanism of spherical $\mathrm{ZnO}$ nanostructures synthesized via colloid chemistry," Physica B, vol. 394, no. 2, pp. 372-376, 2007.
[12] Ö. A. Yildırım and C. Durucan, "Synthesis of zinc oxide nanoparticles elaborated by microemulsion method," Journal of Alloys and Compounds, vol. 506, no. 2, pp. 944-949, 2010.

[13] V. Polshettiwar and R. S. Varma, "Microwave-assisted organic synthesis and transformations using benign reaction media," Accounts of Chemical Research, vol. 41, no. 5, pp. 629-639, 2008.

[14] C. O. Kappe, "Controlled microwave heating in modern organic synthesis," Angewandte Chemie-International Edition, vol. 43, no. 46, pp. 6250-6284, 2004.

[15] I. Bilecka and M. Niederberger, "Microwave chemistry for inorganic nanomaterials synthesis," Nanoscale, vol. 2, no. 8, pp. 1358-1374, 2010.

[16] J. Huang, C. Xia, L. Cao, and X. Zeng, "Facile microwave hydrothermal synthesis of zinc oxide one-dimensional nanostructure with three-dimensional morphology," Materials Science and Engineering B, vol. 150, no. 3, pp. 187-193, 2008.

[17] D. Sharma, S. Sharma, B. S. Kaith, J. Rajput, and M. Kaur, "Synthesis of $\mathrm{ZnO}$ nanoparticles using surfactant free in-air and microwave method," Applied Surface Science, vol. 257, no. 22, pp. 9661-9672, 2011.

[18] R. Al-Gaashani, S. Radiman, N. Tabet, and A. R. Daud, "Effect of microwave power on the morphology and optical property of zinc oxide nano-structures prepared via a microwave-assisted aqueous solution method," Materials Chemistry and Physics, vol. 125, no. 3, pp. 846-852, 2011.

[19] T. D. Canh, N. V. Tuyen, and N. N. Long, "Influence of solvents on the growth of zinc oxide nanoparticles fabricated by microwave irradiation," VNU Journal of Science, MathematicsPhysics, vol. 25, pp. 71-76, 2009. 
[20] L. Wu, Y. Wu, Y. Shi, and H. Wei, "Synthesis of $\mathrm{ZnO}$ nanorods and their optical absorption in visible-light region," Rare Metals, vol. 25 , no. 1, pp. 68-73, 2006.

[21] H. Kleinwechter, C. Janzen, J. Knipping, H. Wiggers, and P. Roth, "Formation and properties of $\mathrm{ZnO}$ nano-particles from gas phase synthesis processes," Journal of Materials Science, vol. 37, no. 20, pp. 4349-4360, 2002.

[22] Z. Hu, G. Oskam, R. L. Penn, N. Pesika, and P. C. Searson, "The influence of anion on the coarsening kinetics of $\mathrm{ZnO}$ nanoparticles," Journal of Physical Chemistry B, vol. 107, no. 14, pp. 3124-3130, 2003.

[23] W. Li, E. Shi, W. Zhong, and Z.-W. Yin, "Growth mechanism and growth habit of oxide crystals," Journal of Crystal Growth, vol. 203, no. 1-2, pp. 186-196, 1999.

[24] S. Yamabi and H. Imai, "Growth conditions for wurtzite zinc oxide films in aqueous solutions," Journal of Materials Chemistry, vol. 12, no. 12, pp. 3773-3778, 2002.

[25] Y. C. Chen and S. L. Lo, "Effects of operational conditions of microwave-assisted synthesis on morphology and photocatalytic capability of zinc oxide," Chemical Engineering Journal, vol. 170, no. 2-3, pp. 411-418, 2011.

[26] K. Nejati, Z. Rezvani, and R. Pakizevand, "Synthesis of ZnO nanoparticles and investigation of the ionic template effect on their size and shape," International Nano Letters, vol. 1, no. 2, pp. 75-81, 2011.

[27] S. Erten-Ela, S. Cogal, and S. Icli, "Conventional and microwave-assisted synthesis of $\mathrm{ZnO}$ nanorods and effects of PEG400 as a surfactant on the morphology," Inorganica Chimica Acta, vol. 362, no. 6, pp. 1855-1858, 2009.

[28] H. Xu, H. Wang, Y. Zhang et al., "Hydrothermal synthesis of zinc oxide powders with controllable morphology," Ceramics International, vol. 30, no. 1, pp. 93-97, 2004.

[29] J. H. Park and S. G. Oh, "Preparation of $\mathrm{CaO}$ as OLED getter material through control of crystal growth of $\mathrm{CaCO}_{3}$ by block copolymers in aqueous solution," Materials Research Bulletin, vol. 44, no. 1, pp. 110-118, 2009.

[30] E. Koushki, M. H. Majles Ara, S. H. Mousavi, and H. Haratizadeh, "Temperature effect on optical properties of colloidal ZnO nanoparticles," Current Applied Physics, vol. 11, no. 5, pp. 1164-1167, 2011. 

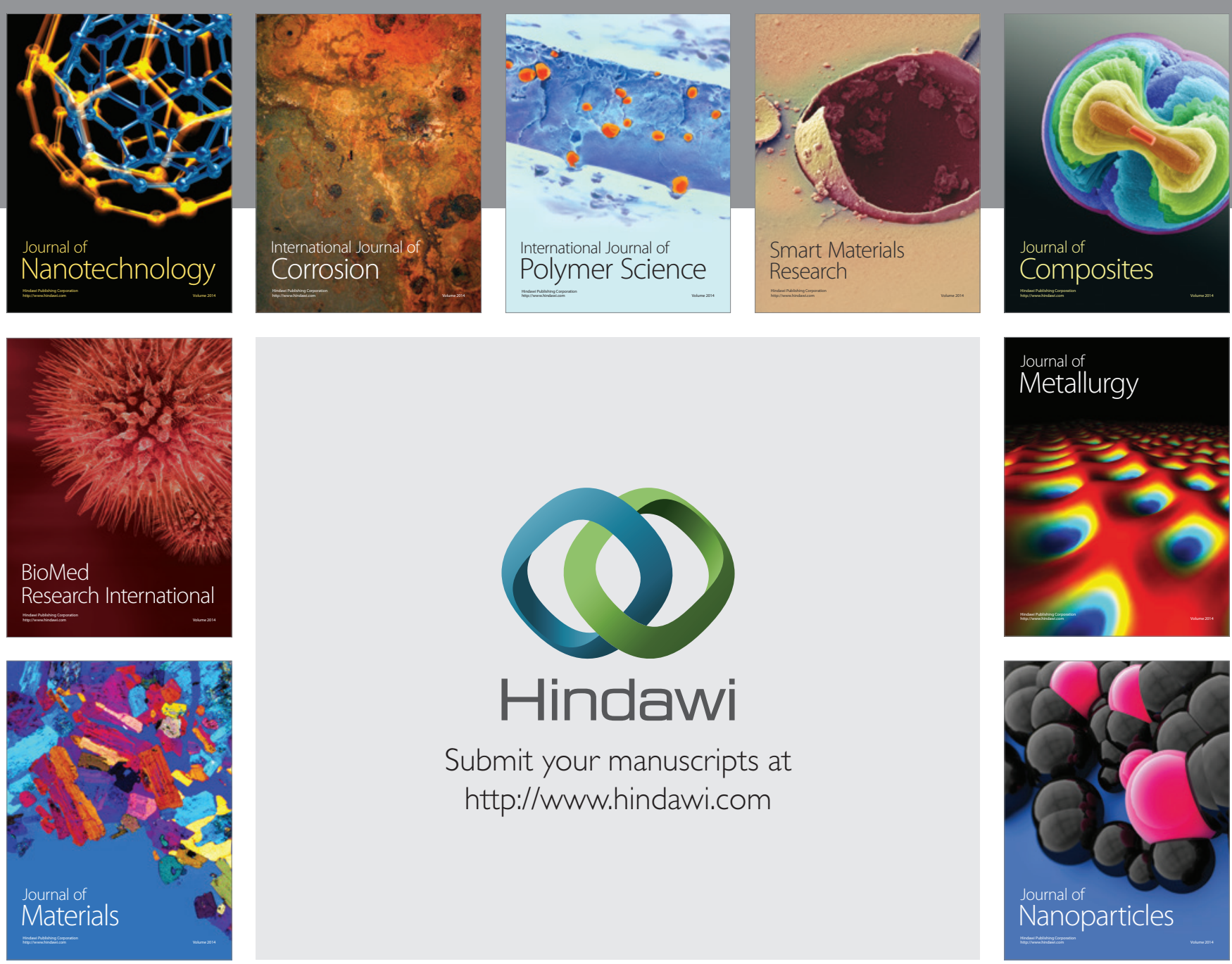

Submit your manuscripts at http://www.hindawi.com
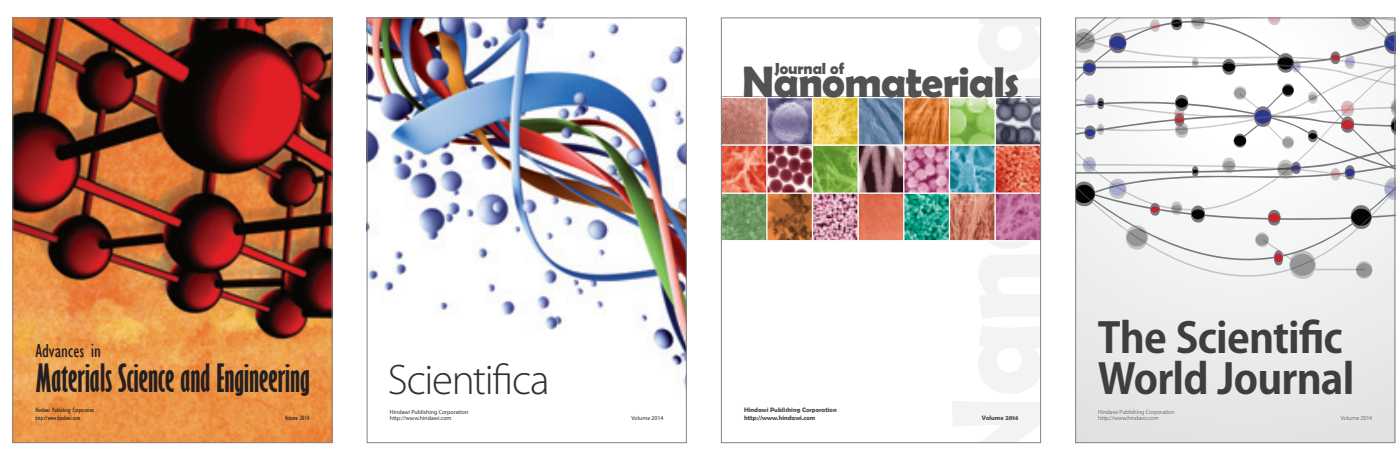

\section{The Scientific World Journal}
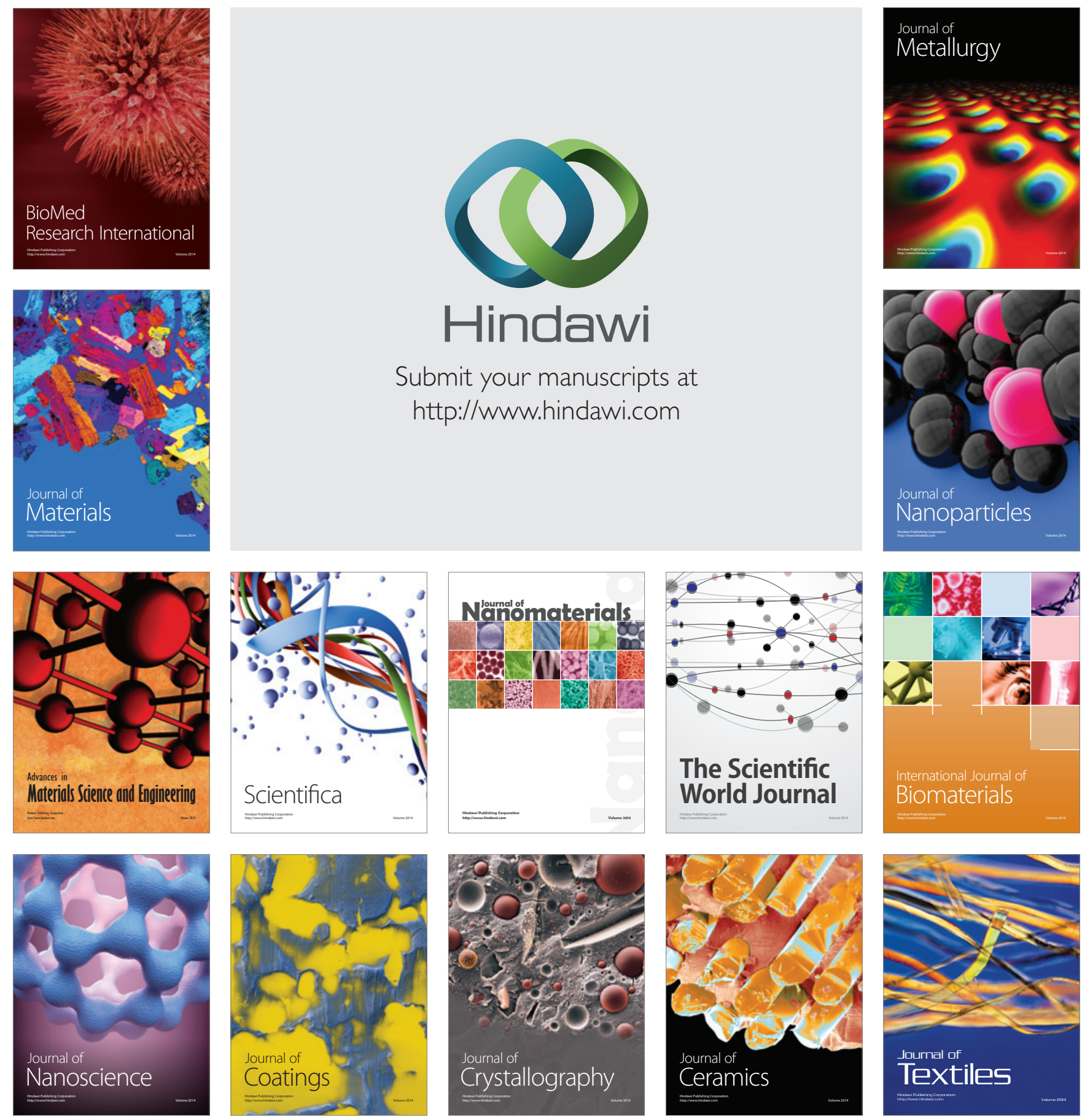